http://jmscr.igmpublication.org/home/ ISSN (e)-2347-176x ISSN (p) 2455-0450

crossref DOI: https://dx.doi.org/10.18535/jmscr/v7i9.71

\title{
Study of effect of jamun (Syzygium cumini) seed powder on glycemic control and dyslipidemia in type 2 diabetes mellitus a double blind randomized control trial
}

\author{
Authors \\ Dr Nidhi Sanwalka ${ }^{1}$, Dr Murlidhar Sharma ${ }^{1}$, Dr Devendra Kumar Jain ${ }^{2}$, \\ Dr Gaurav Bhardwaj ${ }^{3}$, Dr Ramesh Kumar ${ }^{1}$ \\ ${ }^{1}$ Resident, ${ }^{2}$ Professor, ${ }^{3}$ Assistant Professor \\ Department of Medicine Rukmani Devi Beni Prasad Jaipuriya Hospital, Jaipur \\ *Corresponding Author \\ Dr Murlidhar Sharma
}

\begin{abstract}
Objective: to find out the effect of Syzygium cumini (jamun) seed powder on glycemic control and dyslipidemia

Material and Methods: 99 patients with type 2 diabetes mellitus patients with poor glycemic control out of which 50 patients received 10 gms of jamun seed powder supplementation in twice daily dose just before meals along with oral hypoglycemic agents continued as before and 49 patients received placebo with continued oral hypoglycemic agents as before. All the patients were followed up for a total of 90 days,

Result: No significant change in weight, B.M.I., waist circumference, hip circumference, neck circumference and waist hip ratio was noticed. The results of the present study have significantly brought to light the effect of jamun seed powder supplementation in improving glycemic control and dyslipidemia. Being cost effective it may help in improving biochemical parameters of diabetic patients in rural population. However, results need further confirmation by larger studies.

Keywords: Syzygium cumini (jamun), diabetic patients.
\end{abstract}

\section{Introduction}

WHO projects that diabetes will be the 7 th leading cause of death in $2030^{1}$ India leads the world with largest number of diabetic subjects earning the dubious distinction of being termed the "diabetes capital of the world".

Although the prevalence of type 1 and type 2 diabetes mellitus is increasing worldwide, the prevalence of type 2 diabetes mellitus is rising much more rapidly, presumably because of increasing obesity, reduced activity levels as countries become more industrialized and also due to aging of the population. Over the time, diabetes can increase the risk of health-related problems including blindness, kidney damage, nerve damage, amputation of lower limbs and cardio vascular disease ${ }^{2}$. Although diabetes cannot be cured, the disease can be managed by nonpharmacological and pharmacological strategies, where improvements in glycemic control are important factors in delaying the onset and progression of diabetes-related complications ${ }^{3,4}$ 
The major mode of controlling diabetes can be achieved by diet, exercise and/or insulin replacement therapy ${ }^{5,6}$ In modern medical system, managing diabetes without side-effects is still a challenge. In Indian system of folk medicine, more than 100 medicinal plants are mentioned for managing diabetes in which more than one plant in combined way are used for correcting the health disorders and this composite plant extract either in the form of tonic or mixture exhibits a better results than single plant extract treatment ${ }^{7,8}$ Different dietary ingredients having anti-diabetic potentials can act in synergism leading to wider range of control in diabetic patients and their use is particularly important in rural Indian context in reducing the incidence of diabetes related complications? .

Different herbal principles or foods are traditionally used in India in treating diabetes and other diseases. Ayurveda practices recommend Tulsi (Ocimum sanctum), Amla (Emblica officinalis), Bitter Gourd (Momordica charantia), and Jamun (Syzygium cumini) etc. for diabetic patients ${ }^{10,11}$ In India, Syzygium cumini ( $S$. cumini) of the family Myrtaceae has been widely used to treat diabetes by the traditional practioners over many centuries ${ }^{12}$. S. cumini is commonly called jamun, black plum or indian black berry. ${ }^{13}$.

S.cumini seed powder have multimodal actions on many systems, thus isolation of active principle can improve glucose metabolism as well as overall condition of individuals with diabetes not only by hypoglycemic effects but also by improving lipid metabolism and antioxidant status etc. Therefore investigations from traditionally known plants might be useful in clinic or might have novel effects, such as stimulation of $\beta$ cell proliferation. Thus it is possible that novel drugs with novel mechanisms of action may be discovered. This study was conducted the effect of jamun seed powder on glycemic control, dyslipidemia in type 2 diabetes mellitus subjects and control group.

\section{Material and Methods}

The present double blind randomized control trial study was conducted in Department of Medicine. Study was conducted over a period of one year from march 2018 to march 2019.

\section{Methodology}

A total of 113 patients of type 2 diabetes mellitus of any age, either sex, meeting the criteria of study were included in study. Patients of diabetes with cardiovascular, cerebrovascular, liver disease or renal failure were excluded from study to avoid any unknown serious side effects. Patients with sepsis, malignancy or terminally ill patients were also excluded to avoid unforeseen adverse effects, pregnant patients with diabetes were also excluded from study to avoid, if any, harmful effect on fetus. Patients taking insulin for glycemic control were excluded from study as there are chances of self-monitoring and change in dose of insulin according to glycemic levels and thus hindering the study results.

Before enrollment, details about nature and utility of present study were explained to all patients and informed consent was taken. All patients were subjected to detailed clinical examination and relevant investigations. Only after the inclusion and exclusion criteria were met, the subjects were included in the study.

The study was carried out in accordance with the declaration of Helsinki (2000) of the World Medical Association and approved by the local medical ethics committee. Informed consent was obtained from all participants.

All patients fulfilling the inclusion criteria were subjected to receive an interview including age, gender, education level, duration of diabetes, history of smoking, history of drinking alcohol, history of hypertension, and/or dyslipidemia. Medication and supplement use data was obtained for use of lipid-lowering medications, antidiabetes medications, antihypertensive medications through questionnaire and pill bottle reviews. Thereafter patients were evaluated thoroughly regarding vital parameters like temperature, pulse rate, blood pressure, and 
respiratory rate, anthropometric data including height, weight, waist circumference, hip circumference, waist/hip ratio, neck circumference was noted and B.M.I. was calculated. Baseline investigations including fasting and post prandial plasma glucose levels, lipid profile, $\mathrm{HbA1C}$, liver function tests and renal function tests were done. Then they were randomized into two groups- test group and control group. Randomization was done by independent station. Subjects in test group were given jamun seed powder in dose of 5 gms twice daily just before meals, a total of 10 gms daily and control subjects were given placebo powder without having any hypoglycemic effect or effect on dyslipidemia. Then vital parameters, anthropometry, fasting and post prandial plasma glucose level, lipid profile, liver function tests and renal function tests of all the subjects were repeated on $30^{\text {th }}, 60^{\text {th }}, 90^{\text {th }}$ day. All subjects were enquired about any adverse effects at every visit. Anti-diabetic medications were continued as same. Patients and all investigators were blinded to the treatment assigned throughout the study. Patients were advised to report any adverse reactions to treating physician-in-charge of patients. Treatment allocated was enclosed in sealed envelope to which physician in charge of patients had access to only in case of an emergency. Patients with known or newly diagnosed type 2 diabetes of either sex, of any age with poor glycemic control characterized by fasting plasma glucose $>130 \mathrm{mg} / \mathrm{dl}$ and post prandial blood glucose $>180 \mathrm{mg} / \mathrm{dl}$ were included.

- Patients with evidence of coronary artery or cerebrovascular disease, chronic infections, renal disease, malignancy, cirrhosis or decompensated liver disease, pregnant, Critically ill patients, Non-cooperative subjects and Patients taking insulin for diabetes control were excluded.

\section{Measurement Techniques}

- Blood pressure: Weight

- Height: Body mass index (B.M.I.): B.M.I. was calculated by weight/height ${ }^{2}$ (weight in kilograms \& height in metres).

- Waist and hip ratio were taken .All selected subjects underwent an overnight fast of approximately 10 - 12 hours, in the morning fasting blood samples will be taken for plasma glucose and lipidgram (Serum Cholesterol, HDL and Triglycerides). Glucose estimation (Glucose oxidase method).

Plasma glucose was measured on the same day of sample collection by glucose oxidase method. $\mathrm{HbA}_{1 \mathrm{C}}$ level was measured in a random blood sample preserved in EDTA and by liquid chromatography method.

\section{- Serum Lipid Estimation}

\section{Statistical analysis}

All the data obtained during study was subjected to statistical analysis using MSTAT software. Mean and standard deviation were calculated for each studied variable. Unpaired student t-test was performed to assess the significance between test group and control group. ' $t$ ' test analysis was performed to assess whether significant differences existed in biochemical parameters of the subjects in test group and control group. Level of significance was set at $p<0.05$. Data pertaining to duration of study was analyzed using one way anova through INDOSTAT software.

\section{Observations and Results}

The subjects included in this study were recruited from patients 99 out of them, 66 of the participants were males and 33 were females. The age range for the participants was between 30 and 80 years. The mean age in group I was $57 \pm 8.71$ years and in group II was $54 \pm 11.80$ years. Mean duration of diabetes in group I was $7 \pm 2.69$ years and in group II was $6 \pm 3.45$ years The average weight in patients who received S.cumini seed powder supplementation (Group I) was $78 \pm 10.48$ $\mathrm{kg}$, which reduced by $1.29 \%$ and $2.63 \%$ to $77 \pm 10.17 \mathrm{~kg}$ and $76 \pm 10.35 \mathrm{~kg}$ after 60 and 90 days of supplementation with S.cumini seed powder. The average weight of control group was $73 \pm 9.56 \mathrm{~kg}$ which reduced down to $72 \pm 9.57 \mathrm{~kg}$ 
after 60 days. There was a significant difference between average weight of two groups at the beginning of study $(\mathrm{p}=0.014)$, which remain significant even after 90 days of treatment $(\mathrm{p}=0.048)$. Decrease in average weight in Group I was less than critical difference required to be achieved for the value to become statistically significant.

B.M.I. of the patients who received S.cumini seed powder supplementation (Group I) was $72 \pm 9.57$ $\mathrm{kg} / \mathrm{m}^{2}$, which decreased by $3.7 \%$ to $27 \pm 2.87$ $\mathrm{kg} / \mathrm{m}^{2}$. This decrease in B.M.I. was less than the critical difference of $1.15 \mathrm{~kg} / \mathrm{m}^{2}$ required for the value to be considered as significant. There was no change in B.M.I. in control group (Group II). B.M.I. of two groups did not differ significantly $(\mathrm{p}>0.05)$.

Mean waist circumference of patients who received S.cumini seed powder supplementation (Group I) was $99 \pm 8.39 \mathrm{~cm}$ which decrease by $1.02 \%$ to $98 \pm 8.36 \mathrm{~cm}$ after 30 days, which was less than critical difference of $3.22 \mathrm{~cm}$. there was no change in waist circumference in control group. When two groups are compared, it can be observed that $\mathrm{p}>0.05$.

In females, no change in waist circumference was noticed in both groups during study period. When two groups are compared, it can be observed that $\mathrm{p}>0.05$.

According to change in mean hip circumference, the patients who received S.cumini seed powder supplementation (Group I) and those who received placebo (Group II) show no change in mean hip circumference. When two groups are compared, mean hip circumference in test group was $93 \pm 6.86 \mathrm{~cm}$ and in control group was $96 \pm 8.26 \mathrm{~cm}(\mathrm{p}=0.051]$ Patients in Group I show $0.96 \%$ (absolute value $=0.01$ ) decrease in waist hip ratio after 90 days, which was less than critical difference of 3.22. When two groups are compared it can be observed that, mean waist hip ratio in control group was $1.02 \pm 0.06$ and in test group was $1.05 \pm 0.06(\mathrm{p}=0.06)$ on day 0 which decrease in group I to $1.04 \pm 0.066$ after 90 days $(\mathrm{p}=0.23)$. in test group, after supplementation with jamun seed powder for 30 days there was increase in waist hip ratio by $0.99 \%$, which was statistically non-significant (less than critical difference). There was no change in waist hip ratio in control group. When two groups are compared, it can be observed that, mean waist hip ratio in control group was $1.02 \pm 0.083$ and in test group was $1.00 \pm 0.07(\mathrm{p}=0.47)$ on day 0 which increased in test group to $1.01 \pm 0.067$ after 90 days $(\mathrm{p}=0.707)$.

It can be observed from that the patients who received S.cumini seed powder supplementation (Group I) show 2.6\% decrease in mean neck circumference after 90 days, which was less than critical difference of $1.68 \mathrm{~cm}$. There was no change in mean neck circumference of control group. When two groups are compared it can be observed that, mean neck circumference in control group was $37 \pm 4.16 \mathrm{~cm}$ and in test group was $39 \pm 3.64 \mathrm{~cm}(\mathrm{p}=0.126)$ on day 0 , which was decreased in test group after 90 days to $38 \pm 3.67$ $\mathrm{cm}(\mathrm{p}=0.361)$.

There was no change in mean neck circumference both groups. When two groups are compared it can be observed that, mean neck circumference in control group was $35 \pm 5.40 \mathrm{~cm}$ and in test group was $35 \pm 3.04 \mathrm{~cm}(\mathrm{p}>0.05)$.

Table No1 Demographic and baseline characteristics of all randomized subjects

\begin{tabular}{|l|c|c|}
\hline \multirow{2}{*}{ Characteristic } & Group I (n=50) & Group II (n=49) \\
\cline { 2 - 3 } & (Mean \pm SD) & (Mean \pm SD) \\
\hline Age (years) & $57 \pm 8.71$ & $54 \pm 11.81$ \\
\hline Sex (Male / female) & $36 / 14$ & $30 / 19$ \\
\hline Duration of diabetes (years) & $7 \pm 2.69$ & $6 \pm 3.45$ \\
\hline Family history of diabetes (\%) & 66 & 70 \\
\hline Weight (kg) & $78 \pm 10.49$ & $73 \pm 9.56$ \\
\hline B.M.I.(kg/m ${ }^{2}$ ) & $28 \pm 2.97$ & $27 \pm 4.34$ \\
\hline Fasting plasma glucose (mg/dl) & $143 \pm 13.42$ & $141 \pm 9.44$ \\
\hline $\begin{array}{l}\text { Post prandial plasma glucose } \\
\text { (mg/dl) }\end{array}$ & $242 \pm 29.06$ & $232 \pm 27.77$ \\
\hline Glycosylated hemoglobin (\%) & $8.99 \pm 1.39$ & $8.70 \pm 1.17$ \\
\hline Plasma total cholesterol (mg/dl) & $219 \pm 33.60$ & $201 \pm 24.97$ \\
\hline Plasma triglycerides (mg/dl & $184 \pm 39.19$ & $195 \pm 40.84$ \\
\hline Plasma LDL cholesterol (mg/dl) & $150 \pm 26.62$ & $141 \pm 22.46$ \\
\hline $\begin{array}{l}\text { Plasma HDL cholesterol } \\
\text { (mg/dl) }\end{array}$ & $37 \pm 8.02$ & $39 \pm 6.31$ \\
\hline $\begin{array}{l}\text { Plasma VLDL cholesterol } \\
\text { (mg/dl) }\end{array}$ & $35 \pm 6.23$ & $32 \pm 10.45$ \\
\hline
\end{tabular}


Table No 2 Mean weight $(\mathrm{kg})$ of patients with type-2 diabetes mellitus in test group and control group during different visits

\begin{tabular}{|l|c|c|c|c|c|}
\hline & Day 0 & Day 30 & Day 60 & Day 90 & CD $^{\# \#}$ \\
\hline Group I (test) $(\mathrm{n}=50)$ & $78 \pm 10.48$ & $78 \pm 10.26$ & $77 \pm 10.17$ & $76 \pm 10.35$ & 4.06 \\
\hline Group II (control) (n=49) & $73 \pm 9.56$ & $72 \pm 9.54$ & $72 \pm 9.57$ & $72 \pm 9.68$ & 3.81 \\
\hline Percent change in Group I & & 0 & $\downarrow 1.29$ & $\downarrow 2.63$ & \\
\hline Percent change in Group II & & $\downarrow 1.39$ & $\downarrow 1.39$ & $\downarrow 1.39$ & \\
\hline t-value & 2.5 & 3.04 & 2.51 & 2 & \\
\hline p-value & 0.014 & 0.0001 & 0.014 & 0.048 & \\
\hline
\end{tabular}

$p$ value is significant at $p<0.05$

$\# \mathrm{p}$ value between the two groups by unpaired student $t$ test

\#\#CD-critical difference value between the four groups by one way anova

Table No 3 Mean B.M.I. (kg/m2) of patients with type-2 diabetes mellitus in test group and control group during different visits

\begin{tabular}{|l|c|c|c|c|c|}
\hline & Day 0 & Day 30 & Day 60 & Day 90 & CD $^{\# \#}$ \\
\hline Group I (test) $(\mathrm{n}=50)$ & $28 \pm 2.91$ & $28 \pm 2.89$ & $27 \pm 2.87$ & $27 \pm 2.87$ & 1.15 \\
\hline Group II (control(n=49) & $27 \pm 4.34$ & $27 \pm 4.35$ & $27 \pm 4.34$ & $27 \pm 4.39$ & 1.34 \\
\hline Percent change in Group I & & 0 & $\downarrow 3.7$ & $\downarrow 3.7$ & \\
\hline Percent change in Group II & & 0 & 0 & 0 & \\
\hline t-value & 1.35 & 1.35 & 0.012 & 0.012 & \\
\hline p-value & 0.18 & 0.18 & 0.99 & 0.99 & \\
\hline
\end{tabular}

$\mathrm{p}$ value is significant at $\mathrm{p}<0.05$.

$\# \mathrm{p}$ value between the two groups by unpaired student $\mathrm{t}$ test

\#\#CD-critical difference value between the four groups by one way anova

Table No 4 Mean waist circumference $(\mathrm{cm})$ of patients with type-2 diabetes mellitus in test group and control group during different visits

\begin{tabular}{|l|c|c|c|c|c|}
\hline & Day 0 & Day 30 & Day 60 & Day 90 & CD $^{\# \#}$ \\
\hline Group I (test) (n=36) & $99 \pm 8.39$ & $98 \pm 8.36$ & $98 \pm 8.33$ & $98 \pm 8.37$ & 3.91 \\
\hline Group II (control) (n=30) & $97 \pm 7.83$ & $97 \pm 7.83$ & $97 \pm 7.86$ & $97 \pm 7.86$ & 4.05 \\
\hline Percent change in Group I & & $\downarrow 1.02$ & $\downarrow 1.02$ & $\downarrow 1.02$ & \\
\hline Percent change in Group II & & 0 & 0 & 0 & \\
\hline t-value & 0.054 & 0.049 & 0.049 & 0.049 & \\
\hline p-value & 0.957 & 0.961 & 0.961 & 0.961 & \\
\hline In females & & & & & 4.9 \\
\hline Group I (test) (n=14) & $93 \pm 6.72$ & $93 \pm 6.34$ & $93 \pm 6.40$ & $93 \pm 6.41$ & 6.68 \\
\hline Group II (control) (n=19) & $99 \pm 10.39$ & $99 \pm 10.21$ & $99 \pm 10.43$ & $99 \pm 10.48$ & \\
\hline Percent change in Group I & & 0 & 0 & 0 & \\
\hline Percent change in Group II & & 0 & 0 & 0 & \\
\hline t-value & 1.88 & 1.93 & 1.89 & 1.89 & \\
\hline p-value\# & 0.069 & 0.062 & 0.068 & 0.061 & \\
\hline
\end{tabular}

Table No 5 Mean Hip circumference $(\mathrm{cm})$ of patients with type-2 diabetes mellitus in test group and control group during different visits

\begin{tabular}{|l|c|c|c|c|c|}
\hline & Day 0 & Day 30 & Day 60 & Day 90 & CD $^{\# \#}$ \\
\hline Group I (test) (n=50) & $93 \pm 6.86$ & $93 \pm 6.81$ & $93 \pm 6.84$ & $93 \pm 6.95$ & 2.7 \\
\hline Group II (control) (n=49) & $96 \pm 8.26$ & $96 \pm 8.23$ & $96 \pm 8.23$ & $96 \pm 8.26$ & 3.27 \\
\hline Percent change in Group I & & 0 & 0 & 0 & \\
\hline Percent change in Group II & & 0 & 0 & 0 & \\
\hline t-value & 1.97 & 1.97 & 1.97 & 1.97 & \\
\hline p-value $^{\#}$ & 0.051 & 0.051 & 0.051 & 0.051 & \\
\hline
\end{tabular}

$\mathrm{p}$ value is significant at $\mathrm{p}<0.05$

\#\#CD-critical difference value between the four groups by one way anova

\#\#CD-critical difference value between the four groups by one way anova 
Table No 6 Mean waist hip ratio (WHR) of patients with type-2 diabetes mellitus in test group and control group during different visits

\begin{tabular}{|l|c|c|c|c|c|}
\hline & Day 0 & Day 30 & Day 60 & Day 90 & CD $^{\# \# \mid}$ \\
\hline Group I (test) (n=36) & $1.05 \pm 0.066$ & $1.05 \pm 0.066$ & $1.05 \pm 0.065$ & $1.04 \pm 0.066$ & 0.053 \\
\hline Group II (control) (n=30) & $1.02 \pm 0.06$ & $1.02 \pm 0.06$ & $1.02 \pm 0.06$ & $1.02 \pm 0.079$ & 0.054 \\
\hline Percent change in Group I & & 0 & 0 & $\downarrow 0.96$ & \\
\hline Percent change in Group II & & 0 & 0 & 0 & \\
\hline t-value & 1.91 & 1.91 & 1.91 & 1.21 & \\
\hline p-value & 0.06 & 0.06 & 0.06 & 0.23 & \\
\hline In female & Day 0 & Day 30 & Day 60 & Day 90 & CD\#\# \\
\hline Group I (test) (n=14) & $1.00 \pm 0.07$ & $1.01 \pm 0.067$ & $1.01 \pm 0.068$ & $1.01 \pm 0.06$ & 0.03 \\
\hline Group II (control) (n=19) & $1.02 \pm 0.083$ & $1.02 \pm 0.08$ & $1.02 \pm 0.085$ & $1.02 \pm 0.085$ & 0.035 \\
\hline Percent change in Group I & & $\uparrow 0.99$ & $\uparrow 0.99$ & $\uparrow 0.99$ & \\
\hline Percent change in Group II & & 0 & 0 & 0 & \\
\hline t-value & 0.73 & 0.379 & 0.379 & 0.379 & \\
\hline p-value\# & 0.47 & 0.707 & 0.707 & 0.707 & \\
\hline
\end{tabular}

Table No 7 Mean neck circumference $(\mathrm{cm})$ of patients with type-2 diabetes mellitus in test group and control group during different visits

\begin{tabular}{|l|c|c|c|c|c|}
\hline & & & & & \\
\hline In males & Day 0 & Day 30 & Day 60 & Day 90 & CD $^{\text {\#\# }}$ \\
\hline Group I (test) (n=36) & $39 \pm 3.64$ & $39 \pm 3.57$ & $39 \pm 3.55$ & $38 \pm 3.67$ & 1.68 \\
\hline Group II (control) (n=30) & $37 \pm 4.16$ & $37 \pm 4.16$ & $37 \pm 4.16$ & $37 \pm 4.21$ & 2.13 \\
\hline Percent change in Group I & & 0 & 0 & $\downarrow 2.6$ & \\
\hline Percent change in Group II & & 0 & 0 & 0 & \\
\hline t-value & 1.55 & 1.5 & 1.5 & 0.92 & \\
\hline p-value & 0.126 & 0.138 & 0.138 & 0.361 & \\
\hline In females & & & & & \\
\hline & Day 0 & Day 30 & Day 60 & Day 90 & CD $^{\# \# \mid}$ \\
\hline Group I (test) (n=14) & $35 \pm 3.04$ & $35 \pm 2.90$ & $35 \pm 3.03$ & $35 \pm 2.88$ & 2.25 \\
\hline Group II (control) (n=19) & $35 \pm 5.40$ & $35 \pm 5.23$ & $35 \pm 5.23$ & $35 \pm 5.31$ & 3.42 \\
\hline Percent change in Group I & & 0 & 0 & 0 & \\
\hline Percent change in Group II & & 0 & 0 & 0 & \\
\hline t-value & 0.031 & 0.012 & 0.095 & 0.21 & \\
\hline p-value & 0.97 & 0.99 & 0.924 & 0.835 & \\
\hline
\end{tabular}

\section{Discussion}

The present study was carried to find out the effect of Syzygium cumini seed powder on glycemic control and dyslipidemia in type 2 diabetes mellitus patients.

Type 2 diabetes mellitus patients with poor glycemic control; fasting plasma glucose levels $>130 \mathrm{mg} / \mathrm{dl}$ and post prandial plasma glucose $>180 \mathrm{mg} / \mathrm{dl}$, on oral hypoglycemic agents, were included in study after excluding complications of diabetes mellitus and organ failure due to any cause and after taking written consent. Pregnant patients, to avoid unforeseen effect of Syzygium cumini seed powder on fetus, patients on insulin therapy, due to change in plasma glucose levels by little adjustment of insulin dosing, and critically ill patients, due to unstable hemodynamic parameters, were excluded from study.

Study subjects were randomized in two groups, test group (group 1) received Syzygium cumini seed powder and control group (group II) received placebo. In our study total number of patients who completed 90 days follow up duration of study was 99, out of which 66 were males and 33 were female though according to International Diabetes Federation, 2013, report that prevalence of type 2 diabetes is almost equal among male and female, report by Manish Gutch, Syed ${ }^{14}$ states that in most of the north Indian states, male to female ratio is worse because of female feticide due to centuriesold wish to have a male child to carry the family's name forward. Because of the social disfavor 
toward girls, female patients are usually the victims of under reporting, leaving treatment and follow up, and absence of family and social support. Usually diabetes in girls is considered as stigma in the society, and families do not pay attention to their treatment. Mean age of subjects in test group was $57 \pm 8.71$ years and in control group was $54 \pm 11.81$ years. Average duration of diabetes in test group was $7 \pm 2.69$ years in test group and $6 \pm 3.45$ years in control group.

It can be observed from table 2 and 3 that there was $1.29 \%$ and $2.63 \%$ reduction in weight of patients after 60 and 90 days of supplementation with jamun seed powder respectively, which was less than calculated critical difference, so was statistically non-significant, also there was $3.7 \%$ decrease in B.M.I. of test group after 60 days of supplementation with Syzygium cumini which was also statistically non-significant reduction.

Our findings are in contrast to study by Sheba Jeyaraj $^{15}$ to see effect of supplementation with jamun seed powder on B.M.I. of diabetic women after 60 days, she found $2.8 \%$ reduction in B.M.I. which was statistically significant. In our study we found $3.7 \%$ reduction in B.M.I. after 60 days which was found to be statistically nonsignificant. There was no further change in B.M.I. at $90^{\text {th }}$ day. The results may differ due to difference in sample size in our study and study by Sheba Jeyaraj 15(99vs30).We know, as sample size increases, the statistical significance of an effect of a particular magnitude will be greater (the $\mathrm{p}$ value will be smaller). Secondly difference can be due to effect of sex on B.M.I. as study by Sheba Jeyaraj was on women, our study results reflect effect on both male and females. As many factors affecting B.M.I. differ in both sexes like level of work; sedentary or moderate to heavy, hormonal effect etc. other cause of difference may be because both populations included subjects of different ethnic groups.

In pre-clinical study by Singh $\mathrm{N}$, Gupta $\mathrm{M}^{16}$ on alloxan induced diabetic albino rats they found that after supplementation with ethanolic extract of seeds of S.cumini there was increase in body weight and decrease in plasma glucose level.

Mohd. Sufiyan Siddiqui, Bhaskar Sharma and Gurudaya $\operatorname{Ram}^{17}$ in 2014, during their study on alloxan induced diabetic mice, observed that after treatment with Syzygium cumini orally for 21 days, there was significant reduction in body weight and liver, kidney weight besides anti hyperglycemic and anti hyperlipidemic effects.

In our study as it can be observed from table 4, 5, 6 and 7 that change in waist circumference, hip circumference, waist/ hip ratio and neck circumference was less than calculated critical difference, so that was statistically non-significant change. Similarly Sahana D.A et $\mathrm{al}^{19}$ in their study for a total period of 6 months noticed no significant change in waist: hip ratio after supplementation with jamun seed powder. To best of our knowledge we could not find any previous studies to compare other anthropometrical data.

\section{Conclusion}

No significant change in weight, B.M.I., waist circumference, hip circumference, neck circumference and waist hip ratio was noticed. The results of the present study have significantly brought to light the effect of jamun seed powder supplementation in improving glycemic control and dyslipidemia along with improvement in hemodynamic parameters in patients type 2 diabetes mellitus, all of which play a major role in development of complications of diabetes, thus may emerge as potential multi-targeted drug and play a role in reducing morbidity and mortality associated with diabetes. Being cost effective it may help in improving biochemical parameters of diabetic patients in rural population. However, results need further confirmation by larger studies.

\section{Recommendations}

Above results are seen in small number subjects, to study such effects in detail, multicenter study with larger sample size, supplementation dose and time should be planned. 
Bibliography

1. Mathers C, Loncar D. Projections of global mortality and burden of disease from 2002 to 2030. PLoS Med, 2006; 3 (11): e442.

2. Genuth S, Alberti KG, Bennett P, Buse J, Defronzo R, Kahn R et al. Follow-up report on the diagnosis of diabetes mellitus. Diabetes Care 2003; 26.

3. The Effect of Intensive Treatment of Diabetes on the Development and Progression of Long-Term Complications in Insulin-Dependent Diabetes Mellitus. New England Journal of Medicine. 1993; 329 (14): 977-986.

4. UKPDS Group. Intensive blood-glucose control with sulphonylureas or insulin compared with conventional treatment and risk of complications in patients with type 2 diabetes (UKPDS 33). UK Prospective Diabetes Study (UKPDS) Group. Lancet. 1998; 352 (9131): 837-853 (11): 31603167.

5. Pankaj Modi B. Diabetes Beyond Insulin: Review of New Drugs for Treatment of Diabetes Mellitus. Current Drug Discovery Technologies. 2007; 4 (1): 39-47.

6. Sean F Dinneen. Management of type 1 diabetes. The Foundation Years. 2007; 3 (4): 158-163.

7. Mallick C, Chatterjee K, GuhaBiswas M, Ghosh D. Antihyperglycemic effects of separate and composite extract of root of musa paradisiaca and leaf of coccinia indica in streptozotocin-induced diabetic male albino rat. African Journal of Traditional, complementary and alternative medicine 2007; 4(3): 362- 371.

8. Eshrat Halim M. Hypoglycemic, hypolipidemic and antioxidant properties of combination of curcumin from curcuma longa, linn, and partially purified product from abroma augusta, linn. In streptozotocin induced diabetes. Indian
Journal of Clinical Biochemistry 2002; 17(2): $33-43$.

9. Mitra A. Effects of a Composite of Tulsi Leaves, Amla, Bitter Gourd, Gurmur Leaves, Jamun Fruit and Seed in Type 2 Diabetic Patients. jcdr, Year : 2007; 1(6): $511-520$.

10. Marles RJ, Farnsworth NR. Antidiabetic plants and their active constituents. Phytomedicine 1995; 2: 137-189.

11. Prajapati N. A handbook of medicinal plants. Jodhpur: Agrobios (India); 2003.

12. Nadkarni A, Nadkarni K. Dr. K. M. Nadkarni's Indian materia medica. Bombay: Popular Prakashan; 1954; 1331.

13. Chopra RN, Chopra IC, Handa KL, Kapur LD. Indigenous Drugs of India. 2nd edition. U.N Dhur and Sons Pvt. Ltd, Calcutta 1958; 686- 689.

14. Gutch M, Razi SM ,Kumar S, Gupta KK. Diabetes mellitus: Trends in northern India. Indian J Endocrinol Metab. 2014; Sep-Oct; 18(5): 731-734.

15. Jeyaraj S. Effect of jamun seed powder supplementation on the body mass index and fasting plasma glucose levels in woman with type 2 diabetes mellitus. Panacea journal of Health Science Volume1, 2012; 3: 16-20.

16. Singh N, Gupta M., Effects of ethanolic extract of Syzygium cumini (Linn) seed powder on pancreatic islets of alloxan diabetic rats, Indian J Exp Biol. 2007 Oct; 45 (10): 861-867.

17. Sufiyan Siddiqui et al. Anti-hyperglycemic and Anti-hyperlipemia Effects of Syzygium Cumini Seed in Alloxan Induced Diabetes mellitus in Swiss Albino Mice (Mus musculus). Med Aromat Plants 2014; 3: 4.

18. Sufiyan Siddiqui et al. Anti-hyperglycemic and Anti-hyperlipemia Effects of Syzygium Cumini Seed in Alloxan Induced Diabetes mellitus in Swiss Albino 
Mice (Mus musculus). Med Aromat Plants 2014; $3: 4$.

19. Sahana D.A, Shivaprakash G, Raghavendra Baliga, Adhikari Prabha M.R, Jyothi Ganesh , M.R.S.M Pai. Effect of Eugenia Jambolana on Plasma Glucose, Insulin Sensitivity and HDL-C Levels: Preliminary Results of A Randomized Clinical Trial Journal of Pharmacy Research 2010; 3(6): 1268-1270. 